A R C H I V E $\quad$ O F
$\begin{aligned} & \text { VOL. LXI } \\ & \text { Ke.2478/meceng-2014-0027 }\end{aligned}$
$\begin{aligned} & \text { Key words: Large-amplitude vibration, Functionally graded, Euler-Bernoulli beam theory, Finite element method, } \\ & \text { Boundary conditions }\end{aligned}$
Boundary conditions

MEHDI JAVID *, MILAD HEMMATNEZHAD **

\title{
FINITE ELEMENT FORMULATION FOR THE LARGE-AMPLITUDE VIBRATIONS OF FG BEAMS
}

\begin{abstract}
On the basis of Euler-Bernoulli beam theory, the large-amplitude free vibration analysis of functionally graded beams is investigated by means of a finite element formulation. The von Kármán type nonlinear strain-displacement relationship is employed where the ends of the beam are constrained to move axially. The material properties are assumed to be graded in the thickness direction according to the powerlaw and sigmoid distributions. The finite element method is employed to discretize the nonlinear governing equations, which are then solved by the direct numerical integration technique in order to obtain the nonlinear vibration frequencies of functionally graded beams with different boundary conditions. The influences of powerlaw index, vibration amplitude, beam geometrical parameters and end supports on the free vibration frequencies are studied. The present numerical results compare very well with the results available from the literature where possible.
\end{abstract}

\section{Introduction}

The large-amplitude free vibration analysis of beams has been numerously studied by various researchers using analytical and numerical techniques. The preliminary work, concerned with the geometrically nonlinear vibrations of a beam, was performed by (Woinowsky-Krieger, 1950). Employing the elliptic integral solution, he investigated the nonlinear vibrations of hinged-hinged beams with axially immovable ends. This issue was afterwards addressed by several authors using perturbation and Ritz-Galerkin methods (Srinivasan, 1965; Evensen, 1968; Ray and Bert, 1969). There can be found some newer analytical studies on the nonlinear vibrations of beam, which seem to be useful, such as (Azrar et al., 1999; Emam, 2009; Emam

\footnotetext{
* Department of Mechanical Engineering, Germi Branch, Islamic Azad University, Germi, Iran; E-mail: m.cavid@gmail.com

** Faculty of Mechanical Engineering, Takestan Branch, Islamic Azad University, Takestan, Iran; E-mail: m.hemmatnezhad@tiau.ac.ir
} 
and Nayfeh, 2009; Pirbodaghi et al., 2009). The early studies carried out on the finite element (FE) vibration analysis of beams were presented by (Mei, 1972; Mei, 1973). Afterwards, tremendous efforts have been made on finding the FE solutions for this problem. (Venkateswara Rao et al., 1976) formulated the large-amplitude free vibrations of beams and plates by linearizing the quadratic terms in strain-displacement relations without considering the effect of the axial displacement. (Raju et al., 1976) included the effect of the axial displacement into the consideration and used the same linearizing approach as in (Venkateswara Rao et al., 1976).

The similarity of all the above FE formulations is the assumption of the simple harmonic motion (SHM) which results in satisfying the equations of motion only at the instant of maximum amplitude. (Kapania and Raciti, 1989) studied the nonlinear free vibrations of composite beams. In this formulation, they reduced the dynamic FE matrix equation to a scalar equation by using the linear mode shapes obtained with the assumption of the SHM, and finally solved this scalar equation by means of perturbation method. The main deficiency about their formulation was the unsatisfaction of the out-of-plane equilibrium equations. In this direction, (Sing et al., 1990) investigated the problem of nonlinear oscillations of beams by improving the solution procedure of previous FE works. Using the linear mode shape obtained via SHM, they iteratively solved the dynamic FE matrix equation. This leads to the exact satisfaction of the equations corresponding to the axial as well as out-of-plane directions. The converged eigenvector was then used in order to reduce the dynamic FE matrix equation to a scalar nonlinear Duffing-type one, which finally solved using the direct numerical integration technique. (Gupta et al., 2009) presented a relatively simple FE formulation and obtained the nonlinear frequencies of Euler-Bernoulli beams with end supports of any type. Their FE formulation begins with the assumption of the SHM and is consequently corrected by implementing the harmonic balance method (HBM). Afterwards, they continued their work and studied the same problem based upon the Timoshenko beam theory in (Jagadish Babu et al., 2010). However, to the best of authors' knowledge, the number of investigations conducted on the nonlinear vibration of beams made up of functionally graded materials (FGMs) is scarce.

(Xiang and Yang, 2008) carried out a study on the free and forced vibration of FG Timoshenko beams of variable thickness under heat conduction using the differential quadrature method. (Sina et al., 2009) developed a new beam theory within the framework of the first order shear deformation theory to analyze free vibration of FG beams. In their study, the equations of motion are derived using Hamilton's principles, which are solved then using an analytical approach. (Simsek, 2010) investigated the large-amplitude 
vibrations of FG beams under the action of a moving load based on the Timoshenko beam theory. The equations of motion are derived using Lagrange's equation, and finally solved by means of Newmark- $\beta$ method in conjunction with the direct iteration method. (Fallah and Aghdam, 2011) implemented He's variational method to investigate the nonlinear characteristics of FG beams resting on nonlinear elastic foundations where the Euler-Bernoulli assumptions together with von Kármán's strain-displacement relations are employed for deriving the governing equations of motion. To the best of authors' knowledge, the most recent work in the field of FE vibration analysis of FG beams is limited to the linear vibration analysis of these structures using FE method performed by (Alshorbagy et al., 2011). In their work, the equations of motion are derived using the Euler-Bernoulli beam theory and virtual work principle. The material properties of beams assumed to be varying through the thickness or longitudinal directions according to the power-law volume fraction function. They assumed linear shape functions for the axial displacement, while cubic ones for the transverse displacement.

The main impetus of the present study is to implement the FE method for investigating the large-amplitude oscillations of FG beams on the basis of Euler-Bernoulli beam assumptions. The FG beam is considered with different boundary conditions and both ends are constrained to move axially, resulting in the von Kármán type strain-displacement relation. The FG material is composed of steel and alumina, whose properties vary along the thickness direction based upon power-law and sigmoid volume fraction functions. The axial and transverse displacements are assumed to have cubic distributions along the element length. The linear mode corresponding to the fundamental frequency is utilized to reduce the dynamic matrix equation to a scalar one. Finally, the direct numerical integration method (Sing et al., 1990; Sundaresan et al., 1999) is applied for solving this scalar equation. This formulation has been used very recently by (Ansari and Hemmatnezhad, 2012) to perform an exhaustive study on the large-amplitude vibrations of double-walled carbon nanotubes. Finally, the influences of different boundary conditions, power-exponent index and beam's length to the thickness ratio on the nonlinear vibration frequencies of FG beams are examined. A comparison is made also with the available results in the literature and good agreement has been achieved.

\section{Material properties of FG material}

A FG beam of length $L$, width $b$ and thickness $h$ is shown in Fig. 1. It is assumed that the material properties of the beam such as, Young's modulus 
$E$, mass density $\rho$ and Poisson's ratio $v$ vary continuously along the thickness direction across the thickness based on the following relations

$$
\begin{aligned}
& E(z)=E_{s}+E_{a s} V_{f}(z), \quad E_{a s}=E_{a}-E_{s} \\
& v(z)=v_{s}+v_{a s} V_{f}(z), \quad v_{a s}=v_{a}-v_{s} \\
& \rho(z)=\rho_{s}+\rho_{a s} V_{f}(z), \quad \rho_{a s}=\rho_{a}-\rho_{s}
\end{aligned}
$$

where subscripts $s$ and $a$ refer to properties of steel and alumina respectively and $V_{f}(z)$ denotes the volume fraction function which can be defined as following for power-law FGMs

$$
V_{f}(z)=\left(\frac{z}{h}+\frac{1}{2}\right)^{N}
$$

while for sigmoid FGMs, it is given by

$$
V_{f}(z)=\left\{\begin{array}{cc}
1-\frac{1}{2}\left(1-\frac{2 z}{h}\right)^{N} & 0 \leq z \leq \frac{h}{2} \\
\frac{1}{2}\left(1+\frac{2 z}{h}\right)^{N} & -\frac{h}{2} \leq z \leq 0
\end{array}\right.
$$

where $N$ is the power exponent which stands for the material variation profile through the thickness of the beam.

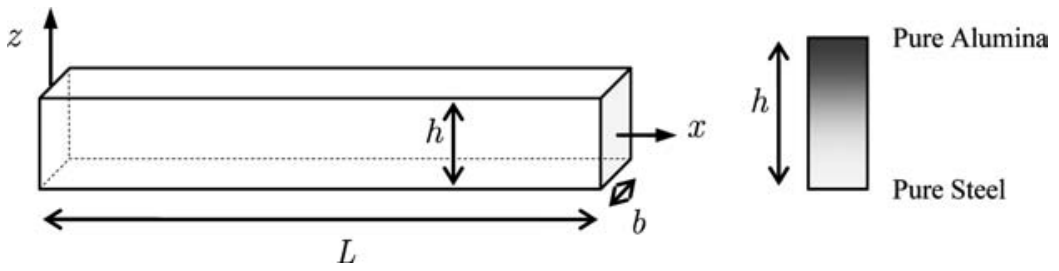

Fig. 1. A schematic view of FG beam

\section{Theoretical formulation}

According to the EBT, the nonlinear strain-displacement relation of the beam at any arbitrary point along the thickness can be written as

$$
\varepsilon_{x}=\frac{\mathrm{d} u_{0}}{\mathrm{~d} x}-z \frac{\mathrm{d}^{2} w_{0}}{\mathrm{~d} x^{2}}+\frac{1}{2}\left(\frac{\mathrm{d} w_{0}}{\mathrm{~d} x}\right)^{2}
$$

where $u_{0}$ and $w_{0}$ are the axial and transverse displacements of the midplane, respectively. The simplified stress-strain relation for a FG beam can be written as

$$
\sigma_{x}=E(z) \varepsilon_{x}
$$


in which $E(z)$ is the Young's modulus of the FG beam. The strain and kinetic energies of the beam are

$$
\begin{aligned}
& U=\frac{1}{2} \int_{0}^{L} \int_{A} \sigma_{x} \varepsilon_{x} \mathrm{~d} A \mathrm{~d} x, \\
& T=\frac{1}{2} \int_{0}^{L} \int_{A} \rho(z)\left[\left(\dot{u}_{0}\right)^{2}+\left(\dot{w}_{0}\right)^{2}\right] \mathrm{d} A \mathrm{~d} x
\end{aligned}
$$

where (.) denotes differentiation with respect to time and $A$ represents the cross-sectional area of the beam.

\section{Finite element formulation for the nonlinear vibrations of FG beams}

The beam is divided into a number of two-node finite elements of equal length $l$. Each node has four degrees of freedom $u, \frac{\mathrm{d} u}{\mathrm{~d} x}, w$ and $\frac{\mathrm{d} w}{\mathrm{~d} x}$. The distributions for $u$ and $w$ are assumed to be of the following form

$$
\begin{aligned}
& u_{0}=N_{1} u_{1}+N_{2} u_{2}+N_{3} u_{3}+N_{4} u_{4}, \\
& w_{0}=N_{1} w_{1}+N_{2} w_{2}+N_{3} w_{3}+N_{4} w_{4}
\end{aligned}
$$

here $N_{i}(i=1, \ldots, 4)$ are the cubic shape functions in terms of the axial coordinate $x$, which are defined as

$$
\begin{aligned}
& N_{1}=\left(\frac{1}{l^{3}}\right)\left(2 x^{3}-3 x^{2} l+l^{3}\right), \\
& N_{1}=\left(\frac{1}{l^{3}}\right)\left(x^{3} l-2 x^{2} l^{2}+l^{3} x\right), \\
& N_{3}=\left(\frac{1}{l^{3}}\right)\left(-2 x^{3}+3 x^{2} l\right), \\
& N_{4}=\left(\frac{1}{l^{3}}\right)\left(x^{3} l-x^{2} l^{2}\right)
\end{aligned}
$$

Substituting Eq. (7) into the strain and kinetic energy equations and applying Hamilton's principle results in the following nonlinear dynamic finite element equation

$$
\left[\begin{array}{cc}
K_{u u} & 0 \\
0 & K_{w w}
\end{array}\right]\left[\begin{array}{c}
u_{i} \\
w_{i}
\end{array}\right]+\left[\begin{array}{cc}
0 & \bar{K}_{u w} \\
\bar{K}_{w u} & 0
\end{array}\right]\left[\begin{array}{c}
u_{i} \\
w_{i}
\end{array}\right]+\left[\begin{array}{cc}
0 & 0 \\
0 & \bar{K}_{w w}
\end{array}\right]\left[\begin{array}{c}
u_{i} \\
w_{i}
\end{array}\right]+\left[\begin{array}{cc}
0 & 0 \\
0 & M
\end{array}\right]\left[\begin{array}{c}
\ddot{u}_{i} \\
\ddot{w}_{i}
\end{array}\right]=\left[\begin{array}{l}
0 \\
0
\end{array}\right]
$$

in which the in-plane/axial nodal quantities denoted by subscript $u$, are kept together while assembling. The subscript $w$ refers to nodal quantities due 
to bending, i.e. $w$ and $\frac{\mathrm{d} w}{\mathrm{~d} x}$. In Eq. (9), $M$ is the element mass matrix, the submatrices $K_{u u}$ and $K_{w w}$ denote the linear stiffness matrices, $\bar{K}_{u w}$ and $\bar{K}_{w u}$ are the first-order stiffness matrices which depend linearly on elemental degrees of freedom, and $\bar{K}_{w w}$ is the second-order stiffness matrix and depends quadratically on elemental degrees of freedom. These submatrices can be evaluated as

$$
\begin{aligned}
& K_{u u}=E A \int_{0}^{l}\left[\frac{\mathrm{d} N_{i}}{\mathrm{~d} x}\right]^{T}\left[\frac{\mathrm{d} N_{i}}{\mathrm{~d} x}\right] \mathrm{d} x, \\
& K_{w w}=E I \int_{0}^{l}\left[\frac{\mathrm{d}^{2} N_{i}}{\mathrm{~d} x^{2}}\right]^{T}\left[\frac{\mathrm{d}^{2} N_{i}}{\mathrm{~d} x^{2}}\right] \mathrm{d} x, \\
& \bar{K}_{u w}=\frac{1}{2} E A \int_{0}^{l}\left(\frac{\mathrm{d} w}{\mathrm{~d} x}\right)\left[\frac{\mathrm{d} N_{i}}{\mathrm{~d} x}\right]^{T}\left[\frac{\mathrm{d} N_{i}}{\mathrm{~d} x}\right] \mathrm{d} x, \\
& \bar{K}_{w u}=E A \int_{0}^{l}\left(\frac{\mathrm{d} w}{\mathrm{~d} x}\right)\left[\frac{\mathrm{d} N_{i}}{\mathrm{~d} x}\right]^{T}\left[\frac{\mathrm{d} N_{i}}{\mathrm{~d} x}\right] \mathrm{d} x, \\
& \bar{K}_{w w}=\frac{1}{2} E A \int_{0}^{l}\left(\frac{\mathrm{d} w}{\mathrm{~d} x}\right)^{2}\left[\frac{\mathrm{d} N_{i}}{\mathrm{~d} x}\right]^{T}\left[\frac{\mathrm{d} N_{i}}{\mathrm{~d} x}\right] \mathrm{d} x, \\
& M=m \int_{0}^{l}\left[N_{i}\right]^{T}\left[N_{i}\right] \mathrm{d} x
\end{aligned}
$$

where $m$ is the mass per unit length of the FG beam and can be obtained from

$$
m=\int_{A} \rho(z) \mathrm{d} A
$$

\section{Method of solution}

Since most of the researches on this topic dealt with the first mode of vibration $[14,15,21,22]$, the present study aims to study the effect of large amplitudes on this fundamental mode of vibration.

To begin with, the linear vibration analysis is performed by discarding all the nonlinear terms in Eq. (9) as

$$
\left[\begin{array}{cc}
K_{u u} & 0 \\
0 & K_{w w}
\end{array}\right]\left[\begin{array}{c}
u_{i} \\
w_{i}
\end{array}\right]+\left[\begin{array}{cc}
0 & 0 \\
0 & M
\end{array}\right]\left[\begin{array}{c}
\ddot{u}_{i} \\
\ddot{w}_{i}
\end{array}\right]=\left[\begin{array}{l}
0 \\
0
\end{array}\right]
$$

The above matrix equation can be readily solved using the assumption of SHM to give the linear vibration frequencies of FG beams. Using the linear stiffness and mass matrices, the linear frequency and eigenvector are obtained. 
The linear mode corresponding to the fundamental frequency is assumed as the spatial distribution for Eq. (9) as

$$
\left\{w_{i}\right\}=\left\{\bar{w}_{i}\right\} A(t)
$$

where $\left\{\bar{w}_{i}\right\}$ is the normalized eigenvector obtained from linear vibration analysis such that the maximum transverse displacement due to bending is unity and $A$ is the maximum displacement at any instant of time. Substituting Eq. (12) into Eq. (9), we arrive at the following relation for the in-plane/axial displacement vector

$$
[u]=\left[K_{u u}\right]^{-1}\left[\bar{K}_{u w}\right][w]
$$

By putting the above relation into Eq. (9) we have

$$
\left[K_{w w}\right]\left[\bar{w}_{i}\right] A+\left\{\left[\bar{K}_{w w}\right]-\left[\bar{K}_{w u}\right]\left[K_{u u}\right]^{-1}\left[\bar{K}_{u w}\right]\right\}\left[\bar{w}_{i}\right] A^{3}+[M]\left[\bar{w}_{i}\right] \ddot{A}=[0]
$$

Pre-multiplying by the transpose of the normalized out-of-plane displacement vector $\left\{\bar{w}_{i}\right\}$ and dividing throughout with $\left[\bar{w}_{i}\right]^{T}[M]\left[\bar{w}_{i}\right]$, we arrive at the following scalar equation

$$
\ddot{A}+\alpha A+\beta A^{3}=0
$$

with $\alpha$ and $\beta$ defined as

$$
\begin{aligned}
& \alpha=\frac{\left[\bar{w}_{i}\right]^{T}\left[K_{w w}\right]\left[\bar{w}_{i}\right]}{\left[\bar{w}_{i}\right]^{T}[M]\left[\bar{w}_{i}\right]}, \\
& \beta=\frac{\left[\bar{w}_{i}\right]^{T}\left\{\left[\bar{K}_{w w}\right]-\left[\bar{K}_{w u}\right]\left[K_{u u}\right]^{-1}\left[\bar{K}_{u w}\right]\right\}\left[\bar{w}_{i}\right]}{\left[\bar{w}_{i}\right]^{T}[M]\left[\bar{w}_{i}\right]}
\end{aligned}
$$

The scalar Duffing-type Eq. (15) is now solved using the Direct Numerical Integration Method $[14,22]$. In this technique, the equation of motion is multiplied by $\dot{A}$ and thus transferred into energy balance equation and then integrated with respect to time. The resulting equation reads as

$$
\dot{A}^{2}+\alpha A^{2}+\left(\frac{\beta}{2}\right) A^{4}=C
$$

Using the condition that $\dot{A}=0$ when $A=A_{\max }$ gives $C=\alpha A_{\max }^{2}+\left(\frac{\beta}{2}\right) A_{\max }^{4}$. Substituting this into Eq. (17), leads the following equation

$$
\mathrm{d} t=\frac{\mathrm{d} A}{\sqrt{\alpha\left(A_{\max }^{2}-A^{2}\right)+\left(\frac{\beta}{2}\right)\left(A_{\max }^{4}-A^{4}\right)}}
$$


Which upon integrating the right side from 0 to $A_{\max }$ yields

$$
T_{N L}=\frac{2 \pi}{\omega_{N L}}=4 \int_{0}^{A_{\max }} \frac{\mathrm{d} A}{\sqrt{\alpha\left(A_{\max }^{2}-A^{2}\right)+\left(\frac{\beta}{2}\right)\left(A_{\max }^{4}-A^{4}\right)}}
$$

Substituting $A=A_{\max } \sin \theta$ and changing the integration limits suitably, Eq. (19) becomes

$$
T_{N L}=\frac{2 \pi}{\omega_{N L}}=4 \int_{0}^{\frac{\pi}{2}} \frac{\mathrm{d} \theta}{\sqrt{\alpha\left[1+\left(\frac{\beta}{2 \alpha}\right)\left(1+\sin ^{2} \theta\right)\right] A_{\max }^{2}}}
$$

The above integral can be computed numerically using the five-point Gaussian quadrature formula to give the nonlinear frequency. The linear frequency can be obtained from

$$
\omega_{L}=2 \pi / \sqrt{\alpha}
$$

\section{Numerical results and discussions}

The FG beam considered here is composed of steel and alumina whose properties vary according to the power-law and sigmoid volume fraction functions. The material properties of steel an alumina are given in Table 1. The beam is divided into a number of 20 finite elements with equal length.

In order to validate the present finite element code, the first three dimensionless linear vibration frequencies $\left(\Omega^{2}=\omega L^{2} \sqrt{\frac{\rho_{s} A}{E_{s} I}}\right)$ for different slenderness ratios and power exponents are listed in Table 2 in comparison with the frequencies obtained from the EBT by (Alshorbagy et al., 2011). This Comparison also illustrates that, except for $N=0$, the results given by (Alshorbagy et al., 2011) go under overestimation compared to the present numerical results. This is mainly due to the fact that, in the later work, linear shape functions were selected for the axial displacement. It can be seen from this table that as $N$ grows up from zero to five, the dimensionless natural frequency reduces. This is due to the deviation of the beam from pure alumina to steel. Further it is observed that the dimensionless frequency slightly change with respect to $L / h$ ratio and this variation is nearly negligible. This is mainly due to the deficiency in EBT for consideration of the shear effects in the analysis.

Table 3 illustrates the effects of three common boundary conditions on the fundamental linear frequencies of power-law FG beams. The boundary conditions considered are simply-simply (SS), clamped-clamped (CC) and clamped-simply (CS). As would be observed, the CC case has the highest 
frequency values amongst the selected boundary conditions. Also, for all kinds of boundary conditions, frequencies decrease as $N$ increases. Further to this, as one travels from $L / h=10$ to $L / h=20$, there can be seen a sudden decrease in the frequency values. However, for higher values of slenderness ratios this decline becomes less steep. Table 4 lists the similar numerical results for sigmoid FG beams. It can be concluded that for the case of sigmoid FGMs, the change in the frequency values with respect to $N$ is not as apparent as in the case of power-law one and the frequency values for this kind of FGM become nearly constant with an increment in the value of power index. The variations of the nonlinear to linear frequency ratios of SS power-law and sigmoid FG beams against the maximum vibration amplitude are illustrated in Figs. 2 and 3, respectively. As it would be observed, in the case of power-law FG beam, the frequency ratios for greater values of $N$ lie between two curves corresponding to $N=0$ and $N=1$. However, in the case of sigmoid counterpart, the nonlinear to linear frequency values increase as $N$ increases. Also, the frequency ratio values increases as the vibration amplitude increases.

Table 1.

Material properties of FGM constituents

\begin{tabular}{|c|c|c|c|}
\hline Properties & Unit & Steel & Alumina $\left(\mathrm{Al}_{2} \mathrm{O}_{3}\right)$ \\
\hline$E$ & $\mathrm{GPa}$ & 210 & 390 \\
\hline$\rho$ & $\mathrm{Kg} / \mathrm{m}^{3}$ & 7800 & 3960 \\
\hline
\end{tabular}

Table 2.

The variation of linear dimensionless frequency parameters for different material distributions and slenderness ratios of power-law FG beams

\begin{tabular}{|c|c|c|c|c|c|c|c|c|}
\hline$L / h$ & $\Omega_{i}$ & & $N=0$ & $N=0.2$ & $N=0.5$ & $N=1$ & $N=2$ & $N=5$ \\
\hline \multirow{6}{*}{20} & \multirow{2}{*}{$i=1$} & Present & 4.3948 & 4.1227 & 3.9035 & 3.7275 & 3.5760 & 3.4122 \\
\hline & & (Alshorbagy et al., 2011) & 4.3425 & 4.2315 & 4.1262 & 4.0359 & 3.9684 & 3.9075 \\
\hline & & Present & 8.7897 & 8.2454 & \begin{tabular}{|l|}
7.8071 \\
\end{tabular} & 7.4549 & 7.1519 & 6.8244 \\
\hline & & (Alshorbagy et al., 2011) & 8.6716 & 8.4500 & 8.2397 & 8.0595 & 7.9245 & 7.8030 \\
\hline & \multirow{2}{*}{$i=3$} & Present & 13.1847 & 12.3683 & 11.7108 & 11.1825 & 10.7279 & 10.2367 \\
\hline & & (Alshorbagy et al., 2011) & 12.9750 & 12.6430 & 12.3280 & 12.0580 & 11.8560 & 11.6750 \\
\hline & & & & & & & & \\
\hline \multirow{6}{*}{50} & \multirow{2}{*}{$i=1$} & Present & 4.3948 & 4.1227 & 3.9035 & 3.7275 & 3.5760 & 3.4122 \\
\hline & & (Alshorbagy et al., 2011) & 4.3444 & 4.2333 & 4.1279 & 4.0377 & 3.9701 & 3.9092 \\
\hline & \multirow{2}{*}{$i=2$} & Present & 8.7896 & 8.2454 & \begin{tabular}{|l|}
7.8071 \\
\end{tabular} & 7.4550 & 7.1519 & 6.8244 \\
\hline & & (Alshorbagy et al., 2011) & 8.6866 & 8.4646 & 8.2539 & 8.0734 & 7.9382 & 7.8165 \\
\hline & \multirow{2}{*}{$i=3$} & Present & 13.1845 & 12.3681 & 11.7107 & 11.1824 & 10.7279 & 10.2367 \\
\hline & & (Alshorbagy et al., 2011) & 13.0250 & 12.6920 & 12.3760 & 12.1050 & 11.9020 & 11.7200 \\
\hline
\end{tabular}


Table 3.

The fundamental linear frequencies for various boundary conditions of a power-law FG beam

\begin{tabular}{|c|c|c|c|c|c|c|}
\hline$L / h$ & Boundary condition & $N=0$ & $N=0.2$ & $N=0.5$ & $N=1$ & $N=5$ \\
\hline \multirow{3}{*}{10} & SS & 282.7457 & 248.8161 & 223.0661 & 203.3979 & 170.4466 \\
\cline { 2 - 7 } & CC & 640.9530 & 563.9994 & 505.5373 & 460.8645 & 386.2506 \\
\cline { 2 - 7 } & CS & 441.7028 & 388.6824 & 348.4194 & 317.6584 & 266.2160 \\
\hline \multirow{7}{*}{20} & SS & 70.6864 & 62.2040 & 55.7665 & 50.8495 & 42.6117 \\
\cline { 2 - 7 } & CC & 160.2383 & 140.9998 & 126.3843 & 115.2161 & 90.5627 \\
\cline { 2 - 8 } & CS & 110.4257 & 97.1706 & 87.1049 & 79.4146 & 66.5540 \\
\hline \multirow{2}{*}{50} & SS & 11.3098 & 9.9526 & 8.9226 & 8.1359 & 6.8179 \\
\cline { 2 - 8 } & CC & 25.6381 & 22.5600 & 20.2215 & 18.4346 & 15.4500 \\
\cline { 2 - 7 } & CS & 17.6681 & 15.5473 & 13.9368 & 12.7063 & 10.6486 \\
\hline
\end{tabular}

Table 4.

The fundamental linear frequencies for various boundary conditions of a sigmoid FG beam

\begin{tabular}{|c|c|c|c|c|c|c|}
\hline$L / h$ & Boundary condition & $N=0$ & $N=0.2$ & $N=0.5$ & $N=1$ & $N=5$ \\
\hline \multirow{3}{*}{10} & SS & 200.4141 & 200.8112 & 201.8817 & 203.3979 & 206.4578 \\
\cline { 2 - 7 } & CC & 454.3163 & 455.1880 & 457.5375 & 460.8645 & 467.5753 \\
\cline { 2 - 7 } & CS & 313.0850 & 313.6938 & 315.3346 & 317.6584 & 322.3465 \\
\hline \multirow{7}{*}{20} & SS & 50.1035 & 50.2028 & 50.4704 & 50.8495 & 51.6145 \\
\cline { 2 - 8 } & CC & 113.5791 & 113.7970 & 114.3844 & 115.2161 & 116.8938 \\
\cline { 2 - 8 } & CS & 78.2713 & 78.4234 & 78.8337 & 79.4146 & 80.5866 \\
\hline \multirow{2}{*}{50} & SS & 8.0166 & 8.0324 & 8.0753 & 8.1359 & 8.2583 \\
\hline & CC & 18.1727 & 18.2075 & 18.3015 & 18.4346 & 18.7030 \\
\cline { 2 - 8 } & CS & 12.5234 & 12.5478 & 12.6134 & 12.7063 & 12.8939 \\
\hline
\end{tabular}




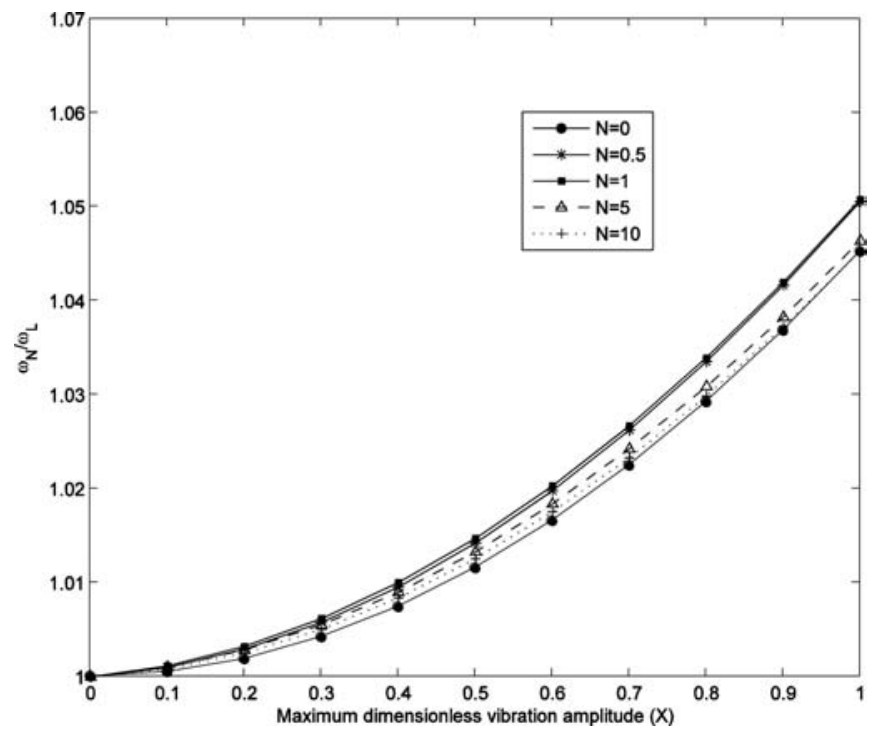

Fig. 2. Effect of power exponent on nonlinear amplitude frequency response curves of SS power-law FG beam

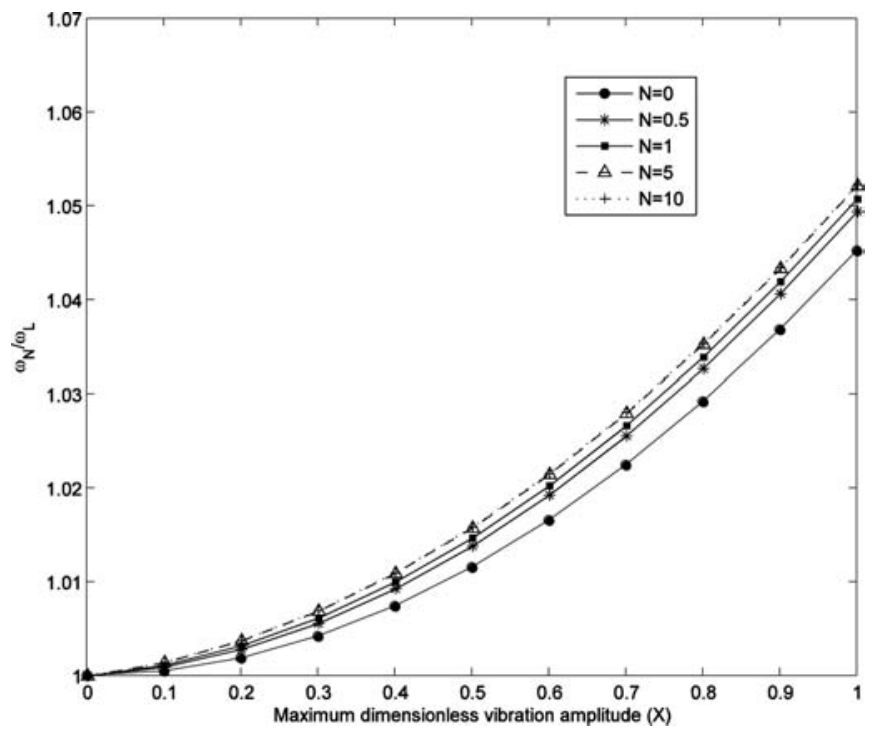

Fig. 3. Effect of power exponent on nonlinear amplitude frequency response curves of SS sigmoid FG beam

\section{Conclusions}

In the present study, the large amplitude vibration analysis of functionally graded beams under various boundary conditions is investigated numerically 
by means of the finite element method. The equations of motion are derived using Hamilton's principle under the assumptions of Euler-Bernoulli beam theory. Using a linear mode shape obtained from simple harmonic oscillation, the dynamic finite element matrix equations have been transformed to a scalar ordinary nonlinear differential equation, which has been solved later by the direct numerical integration technique. The material properties of the beam vary continuously through the thickness according to the power-law and sigmoid volume fraction functions. Comparison of the generated results with those available in the literature shows a good agreement. Numerical results show that as the power exponent increases, the natural frequency values decrease. This is due to the deviation of the beam from pure alumina to steel as $N$ grows up from zero to infinity. As one travels through the end conditions of SS to CC, the influence of boundary conditions is shown to increase the natural frequencies. This is mainly due to the fact that the stiffness of a beam with all edges clamped is higher than that with all edges simple. It can be concluded that for the case of sigmoid FGMs, the change in the frequency values with respect to $N$ is not as apparent as in the case of power-law one and the frequency values for this kind of FGM become nearly constant with an increment in the value of power index. Furthermore, as the vibration amplitude increases, the nonlinearity becomes more prominent and the nonlinear to linear frequency values increase.

Manuscript received by Editorial Board, September 07, 2013; final version, April 03, 2014.

\section{REFERENCES}

[1] Woinowsky-Krieger S.: The effect of an axial force on the vibration of hinged bars. ASME Journal of Applied Mechanics, 17 (1950), 35-36.

[2] Srinivasan A.V.: Large amplitude free oscillations of beams and plates. AIAA Journal, 3 (1965), 1951-1953.

[3] Evensen D.A.: Nonlinear vibrations of beams with various boundary conditions. AIAA Journal, 6 (1968), No. 2, 370-372.

[4] Ray J.D., Bert C.W.: Nonlinear vibration of a beam with pinned ends. Transactions of the American Society of Mechanical Engineers, 91 (1969), 997-1004.

[5] Azrar L., Benamar R., White R.G.: A semi-analytical approach to the nonlinear dynamic response problem of S-S and C-C beams at large vibration amplitudes, part I: general theory and application to the single mode approach to free and forced vibration analysis. Journal of Sound and Vibration, 224 (1999), 183-207.

[6] Emam S.A.: A static and dynamic analysis of the postbuckling of geometrically imperfect composite beams. Composite Structures, 90 (2009), 24-253.

[7] Emam S.A., Nayfeh A.H.: Postbuckling and free vibrations of composite beams. Composite Structures, 88 (2009), 636-642.

[8] Pirbodaghi T., Ahmadian M.T., Fesanghary M.: On the homotopy analysis method for nonlinear vibration of beams. Mechanics Research Communications, 36 (2009), 143-148. 
[9] Mei C.: Nonlinear vibration of beams by matrix displacement method. AIAA Journal, 10 (1972), No. 3, 355-357.

[10] Mei C.: Finite element analysis of nonlinear vibrations of beam columns. AIAA Journal, 11 (1973), 115-117.

[11] Venkateswara Rao G., Kanaka Raju K., Raju I.S.: Finite element formulation for the large amplitude free vibrations of slender beams and orthotropic circular plates. Computers and Structures, 6 (1976), 169-172.

[12] Raju I.S., Venkateswara Rao G., Kanaka Raju K.: Effect of longitudinal or in-plane deformation and inertia on the large amplitude flexural vibrations of slender beams and thin plates. Journal of Sound and Vibration, 49 (1976), 415-422.

[13] Kapania R.K., Raciti S.: Nonlinear vibrations of unsymmetrically laminated beams. AIAA Journal, 27 (1989), No. 2, 201-210.

[14] Singh G., Venkateswara Rao G., Iyengar N.G.R.: Re-investigation of large amplitude free vibrations of beams using finite elements. Journal of Sound and Vibration, 143 (1990), 351355.

[15] Gupta R.K., Jagadish Babu G., Ranga Janardhan G., Venkateswara Rao G.: Relatively simple finite element formulation for the large amplitude free vibrations of uniform beams. Finite Elements in Analysis and Design, 45 (2009), 624-631.

[16] Jagadish Babu G., Gupta R.K., Ranga Janardhan G., Venkateswara Rao G.: Large amplitude free vibration analysis of Timoshenko beams using a relatively simple finite element formulation. Internationa Journal of Mechanical Sciences, 52 (2010), No. 12, 1597-1604.

[17] Xiang H.J., Yang J.: Free and forced vibration of a laminated FGM Timoshenko beam of variable thickness under heat conduction. Composites: Part B, 39 (2008), 292-303.

[18] Sina S.A., Navazi H.M., Haddadpour H.: An analytical method for free vibration analysis of functionally graded beams. Materials and Design, 30 (2009), 741-747.

[19] Simsek M.: Non-linear vibration analysis of a functionally graded Timoshenko beamnunder action of a moving harmonic load. Composite Structures, 92 (2010), 2532-2546.

[20] Fallah A., Aghdam M.M.: Nonlinear free vibration and post-buckling analysis of functionally graded beams on nonlinear elastic foundation. European Journal of Mechanics A/Solids, 30 (2011), 571-583.

[21] Alshorbagy A.E., Eltaher M.A., Mahmoud F.F.: Free vibration characteristics of a functionally graded beam by finite element method. Applied Mathematical Modeling, 35 (2011), 412-425.

[22] Sundaresan P., Singh G., Venkateswara Rao G.: A Simple approach to investigate vibratory behavior of thermally stressed laminated structures. Journal of Sound and Vibration, 219 (1999), No. 4, 603-618.

[23] Ansari R., Hemmatnezhad M.: Nonlinear finite element analysis for vibrations of doublewalled carbon nanotubes. Nonlinear Dynamics, 67 (2012), 373-383.

\section{Sformułowanie metody elementów skończonych dla drgań wielkoamplitudowych w belkach gradientowych}

\section{Streszczenie}

W oparciu o teorię Eulera-Bernouliego przeprowadzono analizę wielkoamplitudowych drgań belki gradientowej posługując się metodą elementów skończonych. Związek między odkształceniem i przemieszczeniem, typu von Kármána, zastosowano tam, gdzie końce belki są utwierdzone i mogą poruszać się osiowo. Zakłada się, że właściwości materiału zmieniają się w kierunku poprzecznym (grubości) zgodnie z funkcją potęgową lub sigmoidalną. Metoda elementów skończonych jest zastosowana $\mathrm{w}$ celu dyskretyzacji nieliniowych równań sterujących, z których po rozwiązywaniu 
metodą bezpośredniego całkowania numerycznego wyznacza się częstotliwości drgań nieliniowych belki gradientowej dla różnych warunków brzegowych. Badany jest wpływ wykładnika funkcji, amplitudy drgań, geometrycznych parametrów belki i podparcia końców na częstotliwości drgań swobodnych. Wyniki numeryczne, przedstawione $\mathrm{w}$ artykule, zgadzają się dobrze $\mathrm{z}$ wynikami podawanymi w dostępnej literaturze. 